\title{
Ildefonso Antonio Bermejo, iniciador del teatro en el Paraguay
}

\begin{abstract}
A UNQUE se ha hecho bastante en el terreno del drama español del siglo XIx, la historia de la literatura dramática de este período tan rico y fecundo dista mucho de ser completa. La mayor parte de los temas literarios han sido tratados, las tendencias del desarrollo literario están delineadas, y las conclusiones sacadas; mas todavía queda un gran número de figuras secundarias y menores cuyas obras están aún por estudiar. Estos dramaturgos, muchos de los cuales gozaron de bastante boga en su tiempo, comprenden gran parte del cuadro total, y hasta que se hayan estudiado sus obras y determinado sus valores literarios, ningún cuadro íntegro de la literatura dramática de este período quedará completo. Hay grandes lagunas entre los hitos dramáticos de este siglo.

Claro que las investigaciones de este género resultarán en su mayoría negativas en cuanto al descubrimiento de materias de valor literario. Sin embargo, es de suma importancia que se registren estos resultados, por negativos que sean, porque de esta manera se pueden revelar los positivos valores literarios aún por descubrir. Con este espiritu se han estudiado las obras dramáticas de Ildefonso Antonio Bermejo: para determinar su valor artístico, y para situar al autor en el hugar que le corresponde en el cuadro del drama español del siglo xix.

Ildefonso Antonio Bermejo nació en la ciudad de Cádiz en 1820. ${ }^{1}$ Aunque estudió derecho, pronto dió evidencias de preferir las actividades literarias, a las cuales iba a dedicar gran parte de su vida.
\end{abstract}


Además de sus actividades de orden literario, también escribió a veces en varios periódicos y revistas. Entre ellos se hallaban $L a$ Epoca, La Liga Nacional, Don Quijote, y El Fraile, en todos los. cuales trabajó como redactor. Sus contribuciones a la postrera publicación nombrada, fueron escritas bajo el seudónimo de "Fray Cándido Medinilla". También colaboró en Flor de la Infancia, La Primera Edad, La Ilustración Católica, Blanco y Negro, y La Ilustración Española y Americana.

Si no se incluyen las contribuciones periodísticas, se puede clasificar su producción literaria en tres categorías principales: el drama, la historia y la novela histórica. La mayor parte de sus obras pertenecen a las dos primeras clasificaciones.

En 1845-1846, Espartero, una novela histórica, fué publicada en dos tomos. Esta sería su primera obra importante, con la que inició un período de actividad literaria que terminó como resultado de la revolución de 1854. Durante este período (1845-1854), se publicaron La revolución de España en su verdadero punto de vista (1846́), en seís tomos; La capa del rey Garcia (1850), novela histórica; y Reseña histórica de la caza (1850). También en el terreno del drama produjo La resurrección de un hombre (1846); El poder de un falso amigo (1849); Al mejor cazador (1850); Cenar a tambor batiente (1850); Llueven hijos (1850); La ley de represalias (1851); La banda de capitán (1851); La consola y el espejo (1852); Ninguno se entiende (1852);. Acertar por carambola (1853).

Como resultado de la revolución de 1854, Bermejo se fué a París, y allí empezó la segunda y muy importante etapa de su vida. En el curso de este mismo año publicó una serie de artículos, bajo el título de Alzamiento popular de 1854. Como el título indica, estos artículos trataban de la sublevación española de ese año, y se publicaron en la Revista Española de Ambos Mundos. Por medio de la publicación de estos artículos, Bermejo llegó a conocer a varios hispanoamericanos que se interesaban en el sostenimiento económico de la dicha revista. Entre ellos se hallaba don Francisco Solano López, Ministro Plenipotenciario del Paraguay en Francia e hijo de1 Presidente del Paraguay. Por instrucciones de su gobierno, don Francisco dió pasos para contratar a varios oficiales militares y a otras personas que fueran de provecho en su patria. Con este pro-- 
pósito of reció a Bermejo una colocación oficial, como consultor en la Secretaría de Relaciones Exteriores del Paraguay. Bermejo la aceptó; llegó al Paraguay en el mes de febrero de 1855, y permaneció allá unos siete años. Por lo visto, durante este período, se dedicó muy poco a actividades literarias. Sin embargo, produjo la comedia Un paraguayo leal, la cual se estrenó en el Teatro Nacional de Asunción, en diciembre de 1858. Bermejo dedicó la pieza a don Carlos Antonio López, Presidente de la República del Paraguay.

A los siete años, Bermejo regresó a España, y una vez más se dedicó a la producción literaria: Una llave y un sombrero, drama que apareció en 1863; Relación explicativa acerca de las investigaciones históricas, geográficas y estadísticas, hechas en varias republicas de la América meridional (1864); Dos cartas y un caracol, comedia (1864); La gallina ciega, comedia (1865); La puerta y el postigo, comedia (1865); Pólvora en salvas, comedia (1866); El capellán de las monjas, comedia (1866); Grandes hechos de la historia universal (1866); La sombra de Torquemada, drama (1867); Contra viento y marea, drama (1868); La carta y el guardapelo, drama (1869); Cortesanos de chaqueta, drama (1869); La estafeta de palacio, historia del reinado de Isabel II, tres tomos (1875-1877); "Matrimonio de Martín Lutero", artículo publicado en 1879 en la $R e$ vista España, tomo LXviII; Historia de la inundación de Levante (1879); A espaldas de su marido, drama (1879); Sin comerlo ni beberlo, drama (1879); Brillantes americanos, drama (1882); Conflictos y tribulaciones de la Compañia de Jesús hasta nuestros días (1887) ; El hijo prestado, drama (1888). Después se publicaron otras dos obras, póstumas: Historia anecdótica y secreta de la corte de Carlos IV, dos tomos (1894); y Curiosidades históricas, costumbres, y tiempos de Mari-Castaña (1897). Bermejo escribió también otras seis comedias que el autor de este trabajo no ha examinado. Son: La providencia, La quinta del tío Bartolo, El ascua con mano ajena, Por tenerle compasión, El vivo retrato, y Jaque-Mate.

Una ojeada a las dedicatorias de las comedias revela los nombres de varios amigos y conocidos del autor, a los más de los cuales se dirige en términos íntimos. Entre ellos se hallan José Fernández Fspino, poeta, catedrático, censor de dramas y diputado; Francisco de Paula Mellado; Gerónimo Muñoz; Francisco Retes, poeta, dramaturgo y político; Mariano Fernández, comediante; Mantuel Fernán- 
dez y González, fecundo novelista ; Elisa Egea de López; Carlos Antonio López, Presidente del Paraguay; doña María Bonaparte, escritora; Juan Martínez Villergas, poeta, periodista y autor satírico; doña Luisa Urquijo de Sedano; Eugenio Lucas, pintor; Tomás Rodríguez Rubí, dramaturgo; Luis Guerra; Emilio Marri, y doña Rosa Butler, poetisa.

La vida de Bermejo fué muy variada, en cuanto a experiencia personal, y se caracteriza por una gran diversidad de intereses. E1 derecho, el periodismo, la política y las actividades literarias reclamaban su atención; pero fué a este último terreno al que Bermejo dedicó la mayor parte de su energía. Murió en Madrid, el 17 de diciembre de 1892.

En el curso de su carrera, Bermejo produjo unas treinta y una comedias, veinte y cinco de las cuales se han examinado como base de este estudio. ${ }^{2}$ Aunque se puede clasificar indefinidamente la mayoría de sus obras dramáticas como altas comedias, un número considerable de ellas abarcan diversos elementos dramáticos que hacen difícil cualquier ensayo de clasificación arbitraria. Salvo la tragedia neoclásica, están presentes en su obra casi todos los elementos comunes a los diversos tipos de drama que existían en España durante el siglo xIx : el romántico, el histórico, el de costumbres, el de tesis, el de melodrama, etc. Once de las comedias están escritas en prosa y catorce en verso.

No es menester examinar aquí, en detalle, todas las comedias que han servido de base para este estudio; basta considerar detalladamente unas cuantas comedias que ejemplifican mejor la capacidad de Bermejo como dramaturgo, y tratar las demás en términos generales.

Ninguno se entiende ${ }^{3}$ (1852) es de un acto y en verso. Su tema es como sigue:

Honorio, pretendiente muy tímido de la encantadora Loreto, no puede reunir el valor suficiente para declararse. Ella le informa a su padre. Diego, que está enamorada, pero que el novio es demasiado asustadizo para proponer matrimonio. El padre cree que Loreto se refiere a Atanasio, campesino muy rico que le ha pedido la mano de su hija. Atanasio aparece vestido en traje de viaje y le informa a 
don Diego que ha venido a despedirse de él; que va a regresar al, campo, ya que está seguro de que Loteto desea darle calabacitas. Diego le aconseja que no parta; que Loreto acaba de informarle que le quiere; que debe cambiatse de ropa, ponerse un traje más apropiado, regresar, y declararse a Loreto. Diego informa a su hija de lo que ha pasado, y ella le dice que se ha equivocado; que ella no ama a Atanasio, sino a Honorio. Luego ella le ruega que interceda en su favor con Honorio y Diego consiente. Honorio pide permiso al padre de Loreto para que ella le enseñe un baile especial que él ha de ejecutar esa misma noche en una fiesta. Loreto alcanza a oír una parte de la conversación, y cree que Honorio le ha pedido su mano. Cuando Diego empieza a informarle de la conversación, ella le dice que ya sabe de lo que se trata. Atanasio llega vestido de gala; Diego le explica el error, y le aconseja que vuelva a ponerse el traje de viaje y regrese, para despedirse. Honorio pregunta a Loreto si su padre le ha informado de su petición y ella le contesta que sí. Luego Honorio principia a rodearle el talle con el brazo para empezar la lección de baile; eila interpreta mal sus intenciones y. le ordena que salga de la casa en seguida. Atanasio aparece y el padre de Loreto le informa que su hija y Honorio han reñido, y que él debe volver a cambiarse de ropa y regresar. Honorio entra, explica la desavenencia, y se efectúa la reconciliación. El pobre de Atanasio vuelve a aparecer vestido de gala. El padre de Loreto le informa sobre lo que ha pasado, y le aconseja que vuelva a ponerse el traje de viaje.

Esta piececilla, aunque carece por completo de pretensiones de valor literario, es bastante divertida $y$, en conjunto, está muy bien hecha. El elemento cómico que constituye el único verdadero mérito de la pieza, está muy bien concebido y ejecutado. Se introduce la mayor parte del humorismo por medio del antiguo y muy gastado recurso de los personajes que hablan con equívocos (at cross purposes) ; pero las situaciones y el diálogo que resultan de eso son divertidos y entretenidos. Los personajes carecen de distinción, pero son adecuados a la pieza. Atanasio, el tipo aldeano tan generalizado en la escena cómica, es el único personaje chistoso, y sirve de blanco para las situaciones cómicas. E1 tono general de la comedia es bastante moderno. La actitud de Diego hacia su hija se parece más a la escena norteamericana del siglo $\mathrm{xx}$ que a la de la España del siglo xrx. En conjunto, aunque no revela habilidad dramática especial, la pieza es agradable y entretenida.

Pólvora en salvas ${ }^{4}$ (1866) es de un acto y escrita en verso. Su. argumento es como sigue: 
E1 coronel, francote y robusto soldado viejo, pregunta a su hija Julia sobre una supuesta intriga amorosa. Ella le informa que Juan de Dios, un andaluz gracioso que es edecán de su padre, le había traído una carta sin firma, pero que ella la había roto. E1 coronel afirma que enviará a Juan de nuevo al cuartel, por esta falta de disciplina. Verónica, modista, muchacha muy lista, llega a la casa para probar a Julia unos vestidos. El coronel recibe una carta, al parecer de un viejo compañero de armas, en la que informa que su hijo está en Madrid y que está enredándose amorosamente con una muchacha de la clase baja. Ruega al coronel que busque a su hijo y que le abra las puertas de su casa. Juan afirma que conoce a tal señor (Sebastián), e informa al coronel dónde tiene su domicilio. Luego se revela que Sebastián, que está enamorado de Julia ha sobornado a Juan, y que éste ha hecho falsificar la carta, como medio eficaz para introducir a Sebastián en la casa. Luego Juan persuade a Verónica que ella haga el papel de la muchacha de la clase baja de quien Sebastián está al parecer enamorado. Sebastián llega, y Juan informa al coronel que Verónica es la muchacha mencionada en la carta. Por haber sido sobornada por Juan, Verónica admite que esto es verdad, y Julia, que ha sido impresionada por Sebastián, se pone furiosa. Luego el coronel trata de sobornar a Verónica, a fin de que ella abandone la idea de seguir sus relaciones amorosas con Sebastián. Juan se coloca detrás del coronel $y$, esperando recibir parte del soborno, le dice por señas a ella que exija más dinero. Cuando Sebastián y Verónica no se reconocen, a pesar de las señales frenéticas de Juan, el coronel empieza a sospechar. En este momento llega el viejo compañero de armas para pedir la mano de Julia, de parte de un pariente" suyo. Resulta que este pariente es Sebastián, y todo acaba felizmente.

Esta piececita, muy divertida, contiene ciertos elementos dignos de notar. El argumento es insignificante, y sirve sólo de vehículo conveniente y aceptable para introducir al personaje más importante de la pieza, es decir, Juan de Dios. Este astuto y gracioso soldado andaluz está magistral y realístamente pintado, y el humorismo que produce es tan natural como chispeante: proviene del personaje mismo, más bien que de situaciones falsas creadas con este propósito. El viejo coronel está bien retratado, así como Verónica, la modista tan práctica. Además, el diálogo y las situaciones dramáticas están bastante bien desarrollados. En suma, esta pieza, por inconsecuente que sea, muestra una interpretación de la comedia ya más juiciosa y madura, que se advierte generalmente en el arte dramático de Bermejo. 
Brillantes americanos ${ }^{5}$ (1882) es de dos actos y está escrita en prosa. El argumento de la pieza va a continuación:

(Acto I) Al regresar de un viaje, Diego, médico y hermano de Alberto, se entera de que la familia de éste, la cual tiene aspiraciones sociales, hace lo posible por entrar en las esferas de la alta sociedad. Teresa, la esposa que aspira a ascender socialmente, es la responsable de esta determinación. Además, se revela que un sobrino extraviado de Diego, Zacarías, a quien el resto de la familia jamás ha visto, regresa a casa con el título de barón. Cuando esto se sabe, el casamiento de Hortensia, la hija de Teresa y Alberto, con un tal Gustavo, hijo de un comerciante tico, se suspende, y los padres de ella la prometen en matrimonio al llamado barón. Zacarías. Ni Hortensia ni su familia han visto jamás a Gustavo. Gustavo llega durante la ausencia de la familia, y los criados lo toman por Zacarías. Luego llega Zacarías, que es un bribón despreciable y no tiene en que caerse muerto. Gustavo le soborna, a fin de que salga, para poder seguir personificándole.

(Acto II) La familia cree que Gustavo es Zacarías, y le da una calurosa bienvenida. Diego llega más tarde y echa en cara a Gustavo que es un impostor. Gustavo le explica a Diego la situación, y éste conviene en ayudarle. Luego, Diego lleva a Zacarías ante la familia, le denuncia como bribón, y sermonea a la familia sobre lo ridículo de sus aspiraciones sociales. Así todo queda aclarado, y Gustavo y Hortensia se casan.

Esta es una piececilla satírica dirigida contra los ridículos trepadores sociales. El argumento es adecuado, pero de importancia secundaria. Sin embargo, los personajes y las situaciones están muy bien presentados, y revelan un mejoramiento considerable sobre las más de sus comedias. Teresa está pintada de manera convincente, como la esposa disparatada con altas aspiraciones sociales. Asimismo es Alberto, su esposo cómico y tonto, quien trata en vano de adaptarse al nuevo orden casero. También Diego está bien retratado, como hombre de sentido común, el raissonneur de la pieza, que reconoce lo ridículo de la situación y que presta ayuda para resolver los problemas. Lorenzo, el tonto criado asturiano, que se convierte de repente en un gentleman's gentleman, es un buen tipo. Tanto los personajes como las situaciones se prestan sin afectación al humorismo, y Bermejo ha mostrado aquí ciertos toques diestros y naturales que generalmente le faltan. Aunque vuelve a utilizar los medios muy gastados de identidad equivocada y el diálogo con equívocos para 
conseguir efectos cómicos, los obtiene principalmente por trazo convincente de los personajes cómicos y ridículos. En estos personajes radica el mérito principal de la pieza.

Se debe mencionar aquí otras dos comedias, no por su valor intrínseco, sino como interesantes ejemplos de autoplagio. Antes de salir para el Paraguay en 1855, Bermejo había escrito en Madrid, en 1849, El poder de un falso amigo, bagatela melodramática de dos actos y en verso. En 1858, tres años después de llegar al Paraguay y nueve después de la publicación de dicha comedia, escribió $U n$ paraguayo leal. Esta es virtualmente una reproducción exacta de aquélla. El argumento y las situaciones dramáticas son idénticos. Solamente se han cambiado los nombres de los personajes, el título de la pieza, el lugar, y unos cuantos incidentes menores. Sin más ni menos, el autor reprodujo la misma comedia, con apariencias de otra nueva, sin mencionar la anterior.

Las ideas expresadas en la dedicatoria de Un paraguayo leal, que dedica al Presidente del Paraguay, son tan interesantes como reveladoras:

Al Exmo, señor Presidente de la República del Paraguay, ciudadano don Carlos Antonio López.

Exmo. Señor:

Hace algún tiempo que hice a las Musas una despedida instantánea; pero ha llegado un momento en que me he visco precisado a demandar su apoyo y cooperación. Desearía que el abandono involuntario en que las he tenido, que el obligatorio desdén con que las he tratado, no produjesen en ellas un acto de despecho y rebeldía, desamparando al poeta en una de sus más honrosas inspiraciones.

Pero no lo espero; la obra que me he propuesto llevar a cabo tiene un fin grandioso, el de abrir las puertas a la literatura dramática paraguaya, y han de haberme ayudado dignamente en una empresa tan benemérita.

Sírvase, pues, señor Presidente, escudar con su ilustre nombre la obra del escritor...

I. A. BERMEJO.

Asunción, 26 de noviembre de $1858 .{ }^{6}$

Teniendo en cuenta lo precedente, parece algo dudoso que el autor se viera precisado a pedir el apoyo y la cooperación de las Musas al escribir esta comedia. Al contrario, su complacencia en entregarse al autoplagio y su reutilización de la visita de las Musas 
a la hora de reestrenar $\mathrm{El}$ poder de un falso amigo, parecen haber sido suficientes. Se debe tener en cuenta que esta segunda comedia. fué "escrita" y producida en el Paraguay unos nueve años después de producir en España dicha comedia en que fué basada.

Otro detalle interesante, en lo tocante a esta comedia, es la existencia de ciertas evidencias que indican como posible que haya sido la primera comedia formal escrita para la escena paraguaya y producida en ella. En la susodicha dedicatoria las siguientes líneas. parecen indicarlo así:

... la obra que me he propuesto llevar a cabo tiene un fin gran-

dioso, el de abrir las puertas a la literatura dramática paraguaya...

En el epílogo del Acto segundo aparecen los siguientes versos:

Acepta, oh pueblo leal,

esta dramática of renda,

que abre la gloriosa senda

del teatro nacional.

Si en realidad esta comedia sirvió para iniciar el drama en el Paraguay, este hecho, sin duda alguna, constituye su mérito más positivo.

A excepción de estas dos últimas comedias, las precedentes son representativas de los esfuerzos más afortunados de Bermejo en al terreno de la composición dramática. Esto en sí mismo sirve de testimonio poco lisonjero al autor, puesto que indica en efecto que se puede relegar la mayoría de sus comedias a las regiones del limbo, sin temor de pérdida literaria. Desgraciadamente, éste es el caso del comediógrafo Bermejo.

En general, los argumentos de sus comedias son de poco mérito y se caracterizan por una repetición constante de situaciones. En todas hay una fastidiosa uniformidad monótona que indica 1lanamente falta de sensibilidad dramática. En esos cuantos casos en los que el argumento fundamental es bueno, su desarrollo desmañado sugiere que lo encontró por accidente. Casi siempre están presentes una falta de motivación, continuidad y desarrollo natural en el argumento. Efectuada la exposición inicial, el argumento se desenvuelve a menudo en una serie espasmódica de situaciones mal re- 
lacionadas entre sí. Muchas de las escenas aisladas están bastante bien pintadas, pero no armonizan de manera lógica y natural.

Lo cómico es el elemento más importante en la mayoría de las comedias, puesto que se halla en ello el objeto primario. Aquí se revelan de sobra la escasez de imaginación y de capacidad inventiva del autor. Una y otra vez utiliza el mismo recurso para crear lo cómico; a saber, la identidad equivocada y el diálogo con equivocos. En muchos casos se emplea de modo muy efectivo este medio; pero su repetición constante disminuye mucho el valor del conjunto artístico.

Salvo unas cuantas excepciones, los personajes son ineficaces e incoloros. Los más son como títeres, y les falta individualidad. Los personajes cómicos e históricos quizás sean los dos tipos más destacados que presenta, aunque son muy pocos. De estos dos tipos, los de aquél son generalmente grotescos y artificiales, mientras que los de éste son muy a menudo figurones a quienes se da cierto aspecto de realidad, al citar unos hechos históricos, relacionados con el personaje de que se trata. Representan todas las clases sociales, desde la gente baja hasta la realeza.

Tanto en la época como en la índole, se identifica el drama de Bermejo con el período de la alta comedia, que floreció desde la iniciación del movimiento romántico hasta el último cuarto del siglo xIx. Fué contemporáneo de varios dramaturgos bien conocidos, dentro de este género: Manuel Bretón de los Herreros, Manuel Eduardo de Gorostiza, Ventura de la Vega y Tomás Rodríguez Rubí. Desgraciadamente, desde el punto de vista de mérito literario, ocupa una posición muy inferior, respecto a los insignes dramaturgos nombrados. En realidad, el valor artístico de la producción dramática de Bermejo es insignificante, y apenas justifica el hecho de sacarle del olvido literario en que se ha hallado durante tantos años. En la escuela dramática del siglo xIx Bermejo queda muy cerca de la última fila.

J. WORTH BANNER, College of William and Mary Williamsburg, Virginia. 


\section{NOTAS}

1 Los datos biográficos fueron sacados de las siguientes fuentes: Enciclopedia Universal Ilustrada, VIrI, 308; Julio Cejador y Frauca, Historia de la lengua y litetatuta castellana, vol 7, pp. 412-413; Revista chilena, 1875, I, 363-364; Manuel Osorio y Bernard, Ensayo de un catálogo de periodistas españoles, p. 45.

2 Las comedias ntilizadas se hallan en las colecciones de Teatro Español, de la Universidad de Carolina del Norte y de Oberlin College.

3 Colección Teatro Español, de la Universidad de Carolina del Norte, vol. 64, núm. 2 .

4 Op. cit., núm. 3.

5 Op, cit., vol. 63, núm. 12.

6 Un paraguayo leal, Asunción, 1858. 
